\title{
A model for ultimate bearing capacity of piles in unsaturated soils under elevated temperatures
}

\author{
Sannith Kumar Thota $^{1}$ and Farshid Vahedifard ${ }^{1, *}$ \\ ${ }^{1}$ Department of Civil and Environmental Engineering, Mississippi State University, MS, USA
}

\begin{abstract}
Geo-energy applications such as energy piles can expose unsaturated, deep foundation soils to elevated temperatures. This paper presents a closed-form equation for the ultimate bearing capacity of piles in unsaturated soils subject to elevated temperatures under drained conditions. For this purpose, a temperaturedependent effective stress model was incorporated into calculations of skin resistance and end bearing resistance of piles. The proposed temperature-dependent model is an extension of the modified $\beta$ method for determining the ultimate pile bearing capacity of unsaturated soils under drained conditions. Employing the proposed model, a parametric study was carried out to evaluate the ultimate pile bearing capacity for hypothetical clay and silt soils at temperatures ranging from $25^{\circ} \mathrm{C}$ to $55^{\circ} \mathrm{C}$. For both clay and silt, the results indicated that the ultimate pile bearing capacity varies with an increase in temperature. Different trends with temperature were observed for clay and silt. A monotonic increase in pile resistance was observed in clays. For silt, the pile resistance increased at relatively low matric suction whereas it decreased at higher matric suctions.
\end{abstract}

\section{Introduction and Background}

Piles improve the mechanical behavior of in situ soils by invoking load transfer to deeper depths, resisting horizontal and uplift movements, and resisting excessive settlement. Piles have been successfully utilized along with emerging geo-energy technologies. Often in these geo-energy applications, the mechanical loads associated with piles occur in conjunction with additional thermal loads, affecting hydro-mechanical properties of the soil surrounding the pile and in turn, the pile resistance. Proper evaluation of pile resistance under elevated temperatures is an important step in the design and analysis of any geo-energy application involving piles.

Previous studies have conducted experimental and theoretical evaluations to better understand the ultimate pile bearing capacity of unsaturated soils under ambient temperature conditions. Among them, Vanapalli and Taylan [1] extended the classical methods $\alpha, \beta$, and $\lambda$ to unsaturated drained and undrained conditions, whilst considering only skin resistance and ignoring end bearing resistance. Uchaipichat [2] performed a parametric study by using a semi-empirical formulation by varying pile capacities installed in unsaturated clay soils in which undrained shear strength controlling pile capacity at various matric suctions were back calculated via laboratory tests. Georgiadis et al. [3] developed a constitutive relationship and implemented into the finite element program to study the influence of partial saturation on pile behavior.

For energy geo-structures (e.g., energy piles, heat exchangers, multipurpose piles), experimental evidence exists that the pile performance is affected by elevated temperatures [4-6]. In geothermal applications involving piles, temperatures can often exceed $50{ }^{\circ} \mathrm{C}$ [6-7]. Consequently, a variation of ultimate pile resistance was observed under higher temperatures. Liu et al. [7] conducted laboratory tests to estimate the influence of temperature on the ultimate pile bearing capacity in dry and saturated sands. They observed that the ultimate pile bearing capacity in these soils would increase with temperature. Conversely, Wang et al. [8] observed a reduction in shaft resistance with temperature in their experimental tests on thermal piles under constant water content. Numerical simulations have also been performed to simulate the response of saturated soils subject to thermo-mechanical loading of geo-energy applications [9-11]. Uchaipichat [12] presented an expression to determine the ultimate pile bearing capacity of unsaturated soils for undrained heating. Most studies in this area are limited to dry or saturated conditions and are not applicable to unsaturated conditions. However, in the

*Corresponding author: farshid@cee.msstate.edu 
aforementioned geo-energy applications, the soil surrounding piles can be under unsaturated conditions. Thus, gaps remain for simple models that can properly capture the effects of temperature on the ultimate bearing capacity of piles in unsaturated soils. A theoretical approach to determine the ultimate bearing capacity of the pile in unsaturated soils under elevated temperatures provides an efficient design and analysis of temperature dependent piles.

This study presents an analytical model for the ultimate bearing capacity of piles in unsaturated soils subject to elevated temperatures under drained conditions. The model was developed by incorporating the temperature dependent effective stress concept into formulations of skin and end bearing resistance of piles for unsaturated soils. To exercise the proposed model, a parametric study was carried out to evaluate the ultimate pile bearing capacity in clay and silt at different temperatures ranging from $25^{\circ} \mathrm{C}$ to $55^{\circ} \mathrm{C}$.

\section{Formulation for Temperature Dependent Ultimate Pile Bearing Capacity of Pile in Unsaturated Soils}

\subsection{Ultimate pile bearing capacity in unsaturated soils (drained condition)}

The ultimate pile bearing capacity in unsaturated soils is one of the key parameters in the design and analysis of pile foundations. In most cases encountered in the field, the soil surrounding piles is in an unsaturated state. The ultimate bearing capacity of piles in unsaturated soils is generally assumed to be comprised of the sum of two components, the shaft capacity, aka skin resistance, and the end bearing capacity, aka tip resistance pile, as given by:

$$
Q_{(\text {unsat })}=Q_{s(\text { unsat })}+Q_{\text {e(unsat })}
$$

where $Q_{\text {(unsat) }}$ is the ultimate bearing capacity of the pile, $Q_{s(u n s a t)}$ is the skin capacity and $Q_{e(u n s a t)}$ is the end bearing capacity. The overall pile resistance can be formulated to unsaturated conditions by extending the well-established conventional methods. A modified $\beta$ method for the ultimate pile bearing capacity of unsaturated soils [1] was utilized and extended to temperature-dependent conditions in this study. The pile resistances are primarily a function of the soil water retention curve (SWRC) and the associated shear strength of the soil. Based on the effective stress principle, the variation of ultimate pile bearing capacity of unsaturated soils under ambient temperature is given by $[1,2]$ :

$$
\begin{aligned}
Q_{(\text {unsat })}= & {\left[c^{\prime}{ }_{a}+\beta\left(\sigma-u_{a}+\psi S_{e}\right)+\psi S_{e}{ }^{\kappa} \tan \delta^{\prime}\right] \pi d L+} \\
& {\left[N_{c}\left(c^{\prime}{ }_{a}+\psi S_{e}{ }^{\kappa} \tan \delta^{\prime}\right)\right] \frac{\pi d^{2}}{4} }
\end{aligned}
$$

where $c_{a}^{\prime}$ is adhesion for saturated conditions $\beta$ is the Burland-Bjerrum coefficient, which is equivalent to $K_{o}$ tan $\delta^{\prime}, K_{o}$ is the coefficient of lateral earth pressure at rest $\left(K_{o}\right.$ $\left.=1-\sin \phi^{\prime}\right), \phi^{\prime}$ is the effective friction angle, $\delta^{\prime}$ is the soilpile interface friction angle, which can be assumed to be about $95 \%$ of $\phi^{\prime}$ in concrete-soil interfaces, $\left(\sigma-u_{a}\right)$ is net normal stress, $\psi$ is matric suction, $\kappa$ is a fitting parameter considered to be 2 [1], $u_{a}$ is pore air pressure, which is assumed to be equivalent to atmospheric pressure, $N_{c}$ is the bearing capacity factor for cohesion intercept taken as 9.0 $[2,13], d$ is the diameter of the pile, and $L$ is the length of the pile. The first term of Eq. 2 represents the contribution from the shaft/skin segment of the pile and the second term represents the contribution from the tip/base segment of the pile.

\subsection{Temperature dependent ultimate pile bearing capacity in unsaturated soils}

Liquid water flow in unsaturated soils can be modelled using Darcy's law. This study combines Darcy's law under the hydrostatic condition with the temperature-dependent Brooks and Corey [14] SWRC model (BC SWRC model) to derive an equation to determine matric suction and effective saturation along the length of the pile under different temperatures.

Temperature can affect matric suction and effective saturation in the soil mass through interfaces of air and water phases and porous fluid structure due to thermally induced drying [15-17]. The variation in properties of pores could further affect the effective stress and, subsequently, the shear strength of the soil $[12,16]$. Effective stress is one of the key parameters controlling the ultimate bearing capacity of unsaturated soils [1]. To consider the changes in effective stress due to thermal variation, the temperaturedependent matric suction and effective saturation recently established by Vahedifard et al. [15-16] and Thota et al. [19] were utilized in this study. The temperature-dependent matric suction is given by $[15,19]$ :

$$
\psi=\gamma_{w} z\left(\frac{\beta_{T_{r}}+T_{r}}{\beta_{c}+T}\right)
$$

where $\beta_{T r}$ and $\beta_{c}$ are regression parameters depending on surface tension and enthalpy of immersion values, $T$ is temperature, $T_{r}$ is reference temperature, $\gamma_{w}$ is the unit weight of water, and $z$ is depth above the water table. In the above equation, $\beta_{T r}$ represents $\beta_{c}$ at $T_{r}$. The evaluation of regression parameters is thoroughly discussed in Vahedifard et al. [15-16]. The above equation considers the effect of temperature on matric suction as a function of temperature dependent surface tension and contact angle through enthalpy of immersion per unit area. Using temperature dependent matric suction [Eq. 3], and the BC SWRC model, the effective saturation, $S_{e}$, is written as [19]:

$$
S_{e}=\left\{\exp \left[-\beta^{\prime} z\left(\frac{\beta_{T_{r}}+T_{r}}{\beta_{c}+T}\right)\right]\right\}^{1 / n}
$$


where $\beta^{\prime}$ is a fitting parameter related to air-entry value and $n$ is a fitting parameter related to pore size distribution. After substituting temperature dependent matric suction [Eq. 3] and effective saturation [Eq. 4] formulations into Eq. 2, the ultimate pile bearing capacity of unsaturated soils under elevated temperatures is given by:

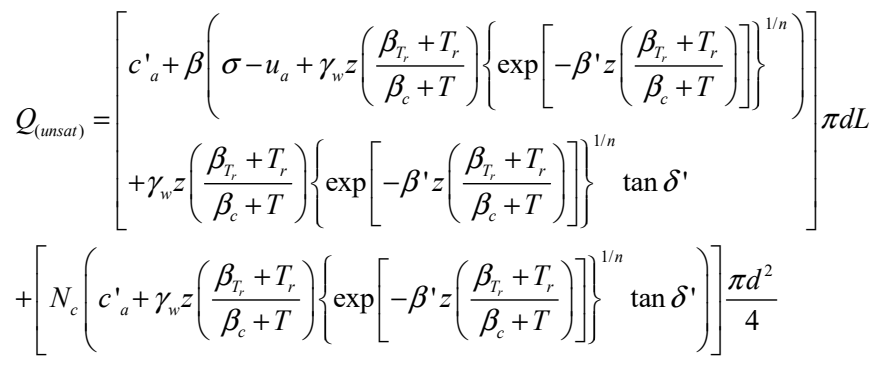

Similar to Eq. 2, the first term in the above equation represents the contribution of the skin or the surface of the pile and the second term represents the contribution of tip or base of the pile to the ultimate pile bearing capacity of unsaturated soils at elevated temperatures. The above equation degenerates to the pile capacity equation at ambient temperature or saturated conditions when the temperature in the pile is at ambient conditions or matric suction is zero, respectively. It is important to note that the formulation is applicable to the pile resistance under equilibrium conditions.

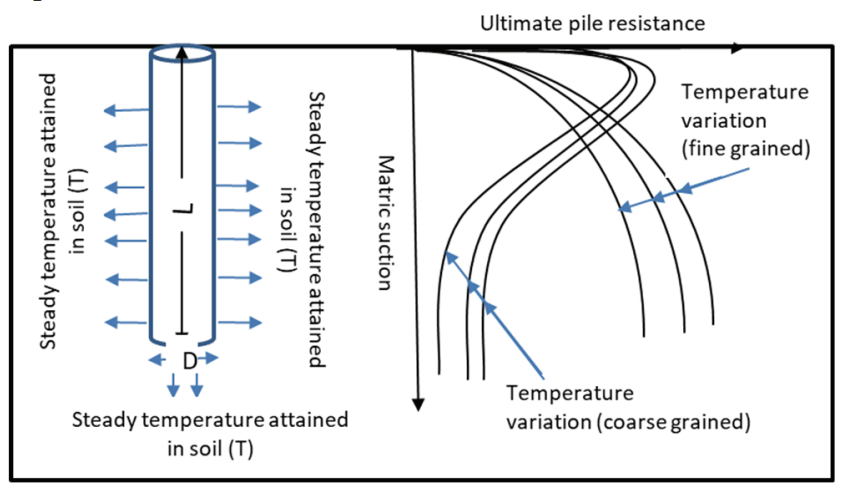

Fig. 1. Schematic diagram of a pile in unsaturated soils under elevated temperatures

Fig. 1 shows the schematic diagram showing a pile embedded in fine- and coarse-grained soils. Due to thermal loading, the pile and the surrounding soil can be subjected to various temperatures. Depending on short-term or longterm loading conditions, the soil can be subjected to either drained or undrained conditions. That is, during mechanical or thermal loading the water is either allowed to drain or restricted. The variation of pile resistance is affected by these conditions of loading. In the current study, long-term (drained) mechanical and thermal loading conditions were assumed. In general, increases in pile temperature in unsaturated soils can affect hydraulic properties and, consequently, the soil behavior surrounding the pile. This will have further impacts on the ultimate bearing capacity of the pile in unsaturated soils. Usually, shaft resistance is mobilized first followed by toe resistance. The mobilization of pile resistance is more prevalent toward the edge of the pile and it gradually decreases as distance from the pile increases radially [19]. Because the porous properties of the soil near the surface of the pile are more susceptible to thermal changes associated with the pile thermal loading, pile resistance fluctuates with matric suction. For a given temperature, the higher the matric suction, the higher the ultimate pile resistance. As known from the proposed formulations, heating the soil would vary the matric suction and the degree of saturation, which, in turn, varies the ultimate bearing capacity of the pile. As shown in Fig. 1, this effect is different depending on the soil type. Based on experimental evidence and theoretical background, the ultimate pile resistance can either decrease or increase depending on drainage conditions, loading history, temperature, the magnitude of matric suction, and soil type $[5-6,8,18,20]$.

\section{Results and Discussion}

The results of the thermally induced variation of effective stress, shaft, end, and ultimate bearing capacities from the proposed equations are presented in this section. Input parameters used for the hypothetical soil types in the analysis are displayed in Table 1 . The temperature range of 25 to $55^{\circ} \mathrm{C}$ is chosen in the current study based on the temperature dependent laboratory tests conducted on energy piles in the literature $[5-8,18,20]$.

Table 1. Input parameters

\begin{tabular}{|c|c|c|c|c|c|c|c|}
\hline \multirow[b]{2}{*}{ Soil } & \multicolumn{6}{|c|}{ Model parameters } & $\begin{array}{l}\text { Geometry } \\
\text { of pile }\end{array}$ \\
\hline & $n$ & $\begin{array}{c}\beta^{\prime} \\
\left(\mathrm{kPa}^{-1}\right)\end{array}$ & $\begin{array}{c}\Delta h_{T_{r}} \\
\left(\mathrm{~J} / \mathrm{m}^{2}\right)\end{array}$ & $\begin{array}{c}c^{\prime}{ }_{a} \\
(\mathrm{kPa})\end{array}$ & $\begin{array}{c}\sigma \\
(\mathrm{kPa})\end{array}$ & $\phi^{\prime}$ & \multirow[t]{3}{*}{$\begin{aligned} L & =10.0 \mathrm{~m} \\
d & =0.3 \mathrm{~m}\end{aligned}$} \\
\hline Clay & 1.5 & 0.05 & \multirow{2}{*}{-0.516} & 20 & 100 & 28 & \\
\hline Silt & 3.0 & 0.1 & & 0 & 100 & 30 & \\
\hline
\end{tabular}

For both soils, the water table was assumed to be at the base of the pile. This implies that at the base, the pile resistance is mainly governed by the effective stress of the saturated soil and above the base, the pile resistance is primarily governed by the effective stress of unsaturated soil. Fig. 2 shows the variation of effective stress in clay and silt soils along the length of the pile at temperatures $25^{\circ} \mathrm{C}$, $40^{\circ} \mathrm{C}$, and $55^{\circ} \mathrm{C}$, respectively. For clay at each temperature, the trend of effective stress monotonically increases as distance from the base of the pile increases. This is due to soil transforming from a saturated to dry state when moving from the base to the ground surface. For silt, two distinct 
behaviors have been observed. First, in the matric suction range close to the air entry suction, the effective stress increases and attains a peak value and second, it decreases with a continued increase in matric suction. For both soils, at the saturated or low suction range, the effective stress is less affected by temperature. As shown in Fig. 2a, for clay soil, after the air entry suction or in the capillary regime (water is in continuous state and the air is in the discontinuous state), at a given distance, the increase in temperature causes an increase in effective stress. For instance, at a distance of $5 \mathrm{~m}$ from the ground surface to the edge of the pile surface, the effective stress increases approximately by $5 \%$, and $14 \%$ by increasing temperature from 25 to 40 to $55^{\circ} \mathrm{C}$. For silt shown in Fig. $2 \mathrm{~b}$, at a distance of $5 \mathrm{~m}$ from the ground surface to the edge of the pile, the effective stress decreases approximately by $2 \%$ and $4 \%$ by increasing temperature from 25 to 40 to $55^{\circ} \mathrm{C}$.
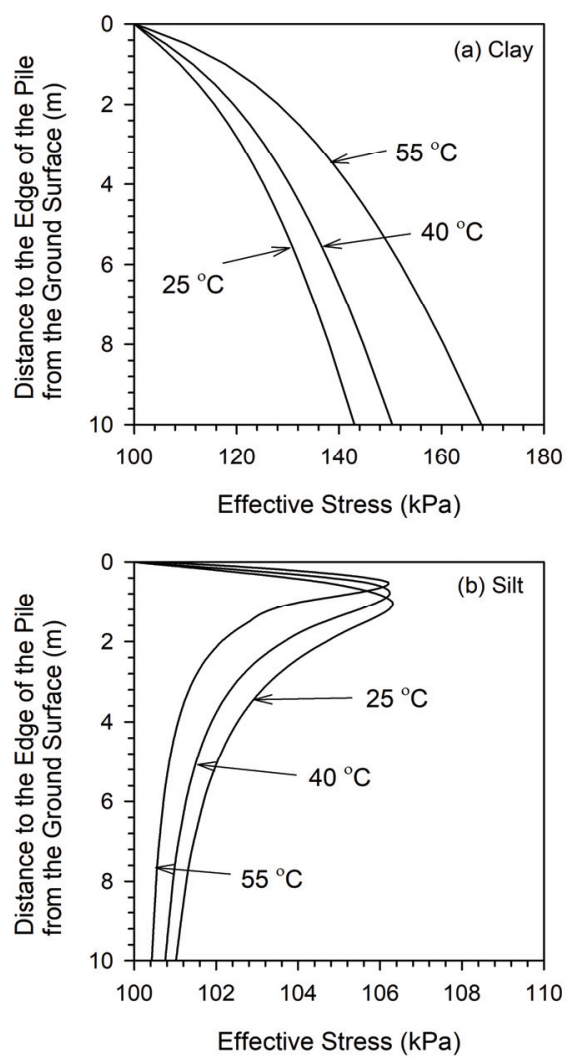

Fig. 2. Profiles of effective stress of unsaturated soils for: (a) clay and (b) silt at temperatures $25^{\circ} \mathrm{C}, 40{ }^{\circ} \mathrm{C}$, and $55^{\circ} \mathrm{C}$.

Fig. 3 shows the variation of shaft capacity, end bearing capacity, and ultimate pile bearing capacity with matric suction of clay at temperatures 25,40 , and $55^{\circ} \mathrm{C}$. Since the shaft and end bearing resistances depend mainly on the variation of the effective stress of the surrounding soil, both have similar trends. At the low matric suction range, the pile resistance is less affected by temperature. At relatively high matric suctions, the increase in temperature causes an increase in shaft capacity, end bearing capacity, and therefore the ultimate pile bearing capacity. At a matric suction of $50 \mathrm{kPa}$, the shaft, end bearing, and ultimate bearing resistances increase approximately by $6 \%, 20 \%$, and $4 \%$ by increasing the temperature from 25 to $40{ }^{\circ} \mathrm{C}$. The same values increase approximately by $15 \%, 5 \%$, and $19 \%$ by increasing the temperature from 25 to $55^{\circ} \mathrm{C}$. An increase in the pile bearing capacity along with an increase in temperature throughout the length of the pile could possibly be due to thermally induced increase in matric suction and thermally induced reduction in water content in the soil surrounding the pile, thus leading to an increase in ultimate resistance at elevated temperatures. The changes in the clay properties associated with temperature can be attributed to the physicochemical variation of pore-water on and around the soil particles.
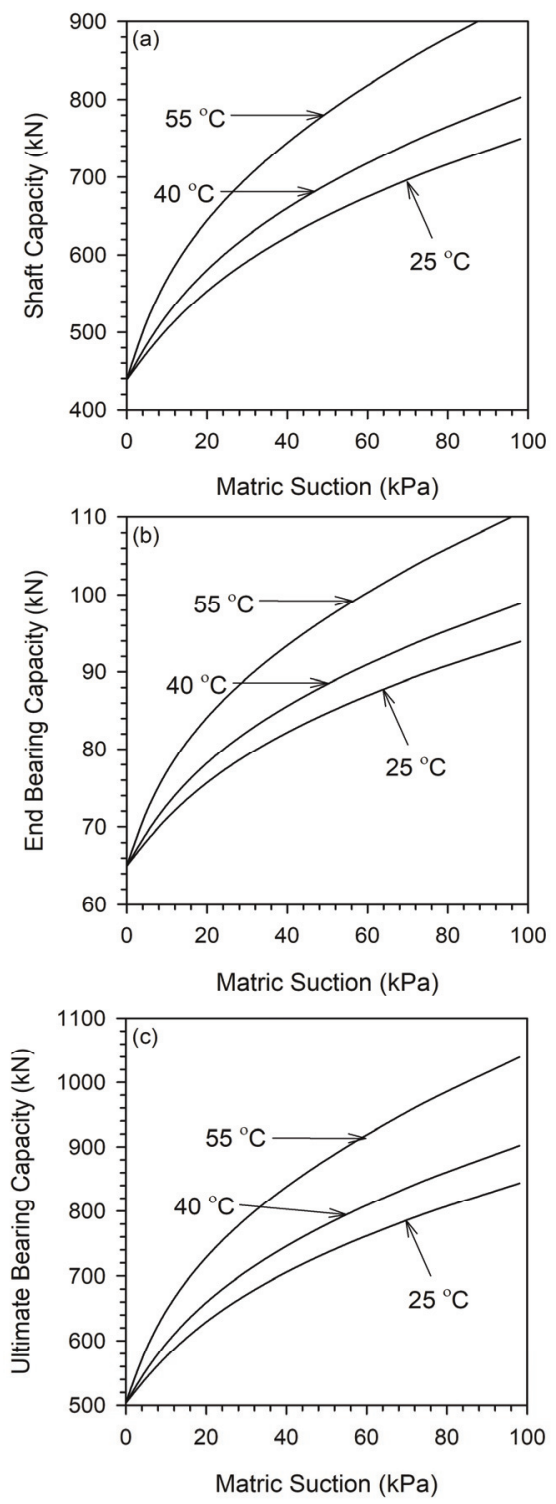

Fig. 3. Relation between matric suction and: (a) shaft capacity, (b) end bearing capacity, (c) ultimate bearing capacity of clay at temperatures $25^{\circ} \mathrm{C}, 40{ }^{\circ} \mathrm{C}$, and $55^{\circ} \mathrm{C}$. 
Fig. 4 shows the variation of shaft capacity, end bearing capacity, and ultimate pile bearing capacity of silt along pile length at temperatures 25,40 , and $55{ }^{\circ} \mathrm{C}$. For a specific temperature, the plots indicate that silt has a non-monotonic behavior. The pile resistance first increases to reach a peak value for relatively low matric suction values and then decreases with a further increase in matric suction. Further, depending on the magnitude of matric suction at different temperatures, unlike clay, the effective stress increases or decreases for the silt soil. The magnitude of variation in pile resistances is relatively lesser than clay. For instance, at a matric suction of $5 \mathrm{kPa}$, the ultimate pile bearing capacity (Fig. $4 \mathrm{c}$ ) increases by $7 \%$ and $8 \%$ by increasing temperature from 25 to 40 to $55^{\circ} \mathrm{C}$, respectively. At relatively higher matric suctions $(>50 \mathrm{kPa})$, shaft capacity, end bearing capacity, and ultimate pile bearing capacity decrease approximately by $1 \%$ and $3 \%$ by increasing the temperature from 25 to 40 and $55{ }^{\circ} \mathrm{C}$, respectively. The effect of temperature on the variation of pile resistance is less at higher matric suction values. This observation agrees with experimental evidence reported by Wang et al. [8] and Kramer and Basu [18] for dry sand, where they reported the minimal effect of temperature on the ultimate capacity of the pile at low water contents.

For both soils, as observed from the results, the major contribution for overall pile resistance is from soil shaft interaction. Therefore, a major percentage increase/decrease in ultimate pile bearing capacity due to elevated temperature is through the shaft of the pile. At a given matric suction, the trend of pile resistance with temperature conforms to some existing experimental data and contradicts with others. From the current study, results regarding silt soil at a higher matric suction agree with the trend observed by Wang et al. [8], however, it contradicts with the trend noted in Liu et al. [6], Kramer and Basu [18], Goode and McCartney [20], and $\mathrm{Ng}$ et al. [5]. On the other hand, the trend of pile resistance at a relatively low suction range of silt and throughout the range of clay soil agrees with those above studies. This could be due to various reasons including some of the tests being conducted under saturated and/or dry conditions. Most of the aforementioned studies tested coarse-grained soils. Testing under different drainage conditions, stress history, confining conditions, and magnitude of matric suction could also affect the trend of effective stress with temperature [12]. Depending on conditions that support thermally induced or dissipation of pore-water pressure in the soil, the peak resistance of the pile can either decrease or increase. To correctly evaluate and further understand the trend of pile resistance, more experimental testing results are needed to examine the pile resistance at various drainage conditions, moisture contents, stress history, and temperatures.

\section{Conclusions}

The ultimate pile bearing capacity for drained unsaturated soils was extended in the paper to account for the effect of temperature. The temperature-dependent effective stress, which is a function of matric suction and effective saturation at elevated temperatures, was incorporated into formulations of shaft capacity, end bearing capacity, and the ultimate pile bearing capacity in unsaturated soils. The matric suction equation considered the thermal effects on the surface tension of water and contact angle through the enthalpy of immersion.
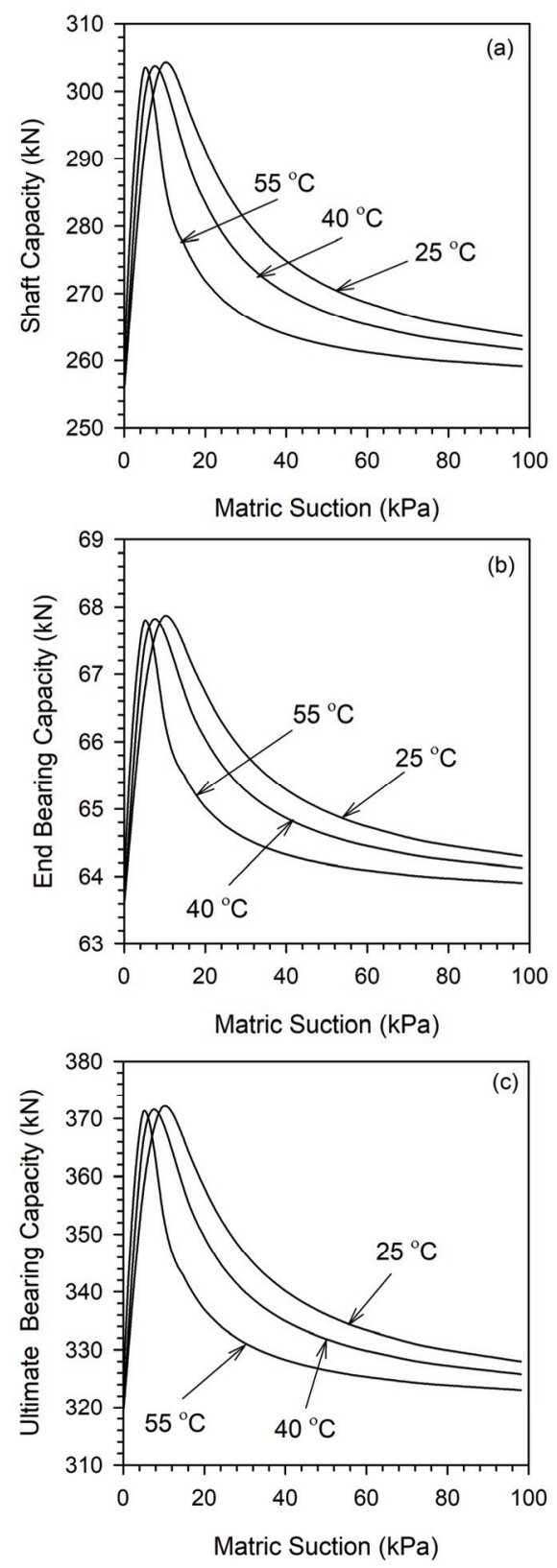

Fig. 4. Relation between matric suction and: (a) shaft capacity, (b) end bearing capacity, (c) ultimate bearing capacity of silt at temperatures $25^{\circ} \mathrm{C}, 40{ }^{\circ} \mathrm{C}$, and $55^{\circ} \mathrm{C}$. 
To demonstrate the effect of temperature on the ultimate pile bearing capacity, a parametric study was conducted on clay and silt soils at temperatures of 25,40 , and $55^{\circ} \mathrm{C}$. The results suggested that elevated temperatures can have a notable effect on the ultimate bearing capacity of the pile in unsaturated soil. Two different trends of ultimate pile bearing capacity with temperature have been observed for the soils considered. However, the variation of magnitude depends on other factors such as confining pressure, stress history, and drainage conditions. Further studies are required to better understand the behavior of unsaturated soil around the pile under combined seepage and thermal conditions. It is also important to consider the effect of coupled water flow, vapor flow and heat transfer mechanisms on overall pile resistance. Nevertheless, the proposed approach provides a simple method to assess the pile ultimate behavior under thermal and hydraulic loading conditions.

\section{Acknowledgment}

This material is based upon work supported by the National Science Foundation under Grant No. CMMI-1634748. Any opinions, findings, and conclusions or recommendations expressed in this material are those of the authors and do not necessarily reflect the views of the National Science Foundation.

\section{References}

[1] S.K. Vanapalli, Z.N. Taylan, "Design of single piles using the mechanics of unsaturated soils. "International Journal of GEOMATE 2, no. 1, 97-204 (2012)

[2] A. Uchaipichat, "Variation of pile capacity in unsaturated clay layer with suction." Electronic Journal of Geotechnical Engineering 17, 2425-2433 (2012)

[3] K. Georgiadis, D.M. Potts, L. Zdravkovic, "The influence of partial soil saturation on pile behaviour." Géotechnique 53, no. 1, 11-25 (2003)

[4] L. Laloui, M. Nuth, L. Vulliet, "Experimental and numerical investigations of the behaviour of a heat exchanger pile." International Journal for Numerical and Analytical Methods in Geomechanics 30, no. 8, 763-781 (2006)

[5] C.W.W. Ng, C. Shi, A. Gunawan, L. Laloui, H.L. Liu, "Centrifuge modelling of heating effects on energy pile performance in saturated sand." Canadian Geotechnical Journal 52, no. 8, 1045-1057 (2014)

[6] H. Liu, C. Wang, G. Kong, A. Bouazza, "Ultimate bearing capacity of energy piles in dry and saturated sand." Acta Geotechnica 14, no. 3, 869-879 (2019)

[7] J.S. McCartney, J.E. Rosenberg, "Impact of heat exchange on side shear in thermo-active foundations." In Geo-Frontiers 2011: Advances in Geotechnical Engineering, 488-498 (2011)
[8] B. Wang, A. Bouazza, D. Barry-Macaulay, M. R. Singh, M. Webster, C. Haberfield, G. Chapman, S. Baycan, "Field and laboratory investigation of a heat exchanger pile." In GeoCongress 2012: State of the Art and Practice in Geotechnical Engineering, 4396-4405 (2012)

[9] A. Di Donna, L. Laloui, "Soil response under thermomechanical conditions imposed by energy geostructures." Energy Geostructures: Innovation in Underground Engineering, 3-21 (2013)

[10] R. Fuentes, N. Pinyol, E. Alonso, "Effect of temperature induced excess porewater pressures on the shaft bearing capacity of geothermal piles." Geomechanics for Energy and the Environment 8, 30-37 (2016)

[11] Z. Fu, "Thermo-Hydro-Mechanical Effects on the Behaviour of Unsaturated Soil-Structure Interfaces and the Numerical Analysis of Energy Piles." PhD diss., Université d'Ottawa/University of Ottawa (2017)

[12] A. Uchaipichat, N. Khalili,"Experimental investigation of thermo-hydro-mechanical behaviour of an unsaturated silt." Géotechnique 59(4), 339-353 (2009)

[13] L. Laloui, and A.F.R. Loria, Analysis and Design of Energy Geostructures: Theoretical Essentials and Practical Application. Academic Press (2019)

[14] R.H. Brooks, A.T. Corey, "Properties of porous media affecting fluid flow." Journal of the irrigation and drainage division 92(2), 61-90 (1966)

[15] S.A. Grant, A. Salehzadeh, Calculation of temperature effects on wetting coefficients of porous solids and their capillary pressure functions. Water Resour. Res., 32, 2, 261-270 (1996)

[16] F. Vahedifard, T.D. Cao, S.K. Thota, E. Ghazanfari, Nonisothermal Models for Soil-Water Retention Curve. J. Geotech. Geoenviron. Eng., 144, 9 (2018)

[17] F. Vahedifard, T.D Cao, E. Ghazanfari, S.K. Thota, Closed-Form Models for Nonisothermal Effective Stress of Unsaturated Soils. J. Geotech. Geoenviron. Eng., 145, 9 (2019)

[18] C.A. Kramer, P. Basu, "Performance of a model geothermal pile in sand." In Proc. 8th Int. Conf. on Physical Modelling in Geotechnics, Perth (Gaudin, C. \& White, D.(eds)). Leiden: CRC Press/Balkema, 771777 (2014)

[19] S.K. Thota, T.D. Cao, F. Vahedifard, E. Ghazanfari, Stability Analysis of an Unsaturated Silty Slope under Nonisothermal Conditions. In Geo-Congress 2019: Geotechnical Materials, Modeling, and Testing, 844852 (2019)

[20] J.C. Goode III, J.S. McCartney, Centrifuge modeling of end-restraint effects in energy foundations. Geotechnical and Geoenvironmental Engineering, 141(8) (2015). 